\title{
Correlation between paddy rice growth and satellite-observed methane column abundance does not imply causation
}

\author{
Zhao-Cheng Zeng ${ }^{1,2 \bowtie}$, Brendan Byrne ${ }^{3 凶}{ }^{3 凶}$, Fang-Ying Gong ${ }^{2}$, Zhonghua He ${ }^{4}$ \& Liping Lei ${ }^{5}$ \\ ARISING FROM Zhang et al. Nature Communications (https://doi.org/10.1038/s41467-019-14155-5) (2020)
}

\begin{abstract}
$\mathrm{n}$ a recent study, Zhang et al. $^{1}$ found paddy rice area and growth were strongly correlated with $\mathrm{CH}_{4}$ column-averaged dry-air mole fractions $\left(\mathrm{XCH}_{4}\right)$ observed from satellites in Monsoon Asia. Based on these correlations, they argued that the spatial area and growth cycle of paddy rice drive the spatial distribution and seasonality of $\mathrm{XCH}_{4}$ in the region of the rice paddies. Here, by reanalyzing satellite $\mathrm{XCH}_{4}$ observations and running $\mathrm{CH}_{4}$ simulations with a chemical transport model, we show that (1) local variation in $\mathrm{XCH}_{4}$ is primarily driven by large scale $\mathrm{CH}_{4}$ flux signals advected into the local area rather than from local emission, indicating that variations in $\mathrm{XCH}_{4}$ do not simply translate to variations in the underlying rice paddy emissions. (2) Spatial correlations between rice paddy extent and $\mathrm{XCH}_{4}$ are confounded by cross-correlation with other $\mathrm{XCH}_{4}$ emission sources that have similar spatial structures. As a result, the spatial and temporal consistencies between rice paddies and $\mathrm{XCH}_{4}$ reported in Zhang et al. ${ }^{1}$ do not imply a causal relationship. The inference of emissions based on the correlation may lead to incorrect conclusions on the annual variabilities of rice paddy $\mathrm{CH}_{4}$ emissions in Monsoon Asia.
\end{abstract}

The space-based instruments Greenhouse gases Observing SATellite Thermal And Near-infrared Sensor for carbon Observation-Fourier Transform Spectrometer (GOSAT TANSO-FTS) and SCanning Imaging Absorption spectroMeter for Atmospheric CHartographY (SCIAMACHY) measure the column-averaged dryair mole fraction of $\mathrm{CH}_{4}$, which is the ratio of vertical column densities (VCDs) between $\mathrm{CH}_{4}$ and dry air weighted by a column averaging kernel ${ }^{2,3}$. VCD is defined as the total number of molecules per unit area in a vertical column from the surface to the top of the atmosphere. The $\mathrm{XCH}_{4}$ observed from space is given by

$$
\mathrm{XCH}_{4}=f\left(\frac{\mathrm{CH}_{4} \mathrm{VCD}}{\text { DryAirVCD }}\right)
$$

in which $f(\cdot)$ is the satellite measurement operator for averaging kernel convolution. Therefore, the variability of $\mathrm{XCH}_{4}$ is subjected to any possible changes of $\mathrm{CH}_{4}$ at different altitudes due to atmospheric transport, apart from the surface layer emissions. Previous studies have shown the significant impact of long-range transport on $\mathrm{XCO}_{2}$ variability ${ }^{4-6}$ ) and the same mechanism can be applied to $\mathrm{XCH}_{4}$. In the northern extratropics, the atmospheric zonal mixing time is estimated to be about 2 weeks ${ }^{7}$, which is much shorter than the seasonal cycle of $\mathrm{CH}_{4}$ fluxes. As a result, the seasonal variability of $\mathrm{XCH}_{4}$ observed at any specific location can be driven by the large scale advected signal instead of the local signal from the underlying surface methane flux. To quantify the relative contribution of a local and external signal, we conducted a tagged tracer simulation using the greenhouse gas framework-Flux (GHGF-Flux) forward model (see "Methods" and Supplementary Fig. 1) for the four regions of interest (ROIs) in Zhang et al. ${ }^{1}$, including Northeast China, Southeast China, North Bangladesh, and North India, as shown in Fig. 1a. We can see that the external contribution to the seasonal cycle of $\mathrm{XCH}_{4}$ outweighs the local contribution for Northeast China, Southeast China, and North India, while they are comparable in North Bangladesh. To further investigate the drivers of $\mathrm{XCH}_{4}$ seasonal variability, Fig. $1 \mathrm{~b}$ shows the monthly averaged $\mathrm{XCH}_{4}$ in the four ROIs and the corresponding zonal means of $\mathrm{XCH}_{4}$ over latitudinal bands centered on the ROIs. The local $\mathrm{XCH}_{4}$ seasonal variabilities are strongly correlated $(p$ value $<0.01)$ with the zonal mean seasonal cycle in all four ROIs despite considerable scatter due to retrieval error and synoptic-scale $\mathrm{XCH}_{4}$ variability. Such agreement is expected since the seasonal cycle of $\mathrm{XCH}_{4}$ has previously been shown to have strong zonal features (Supplementary Fig. 2; ref. ${ }^{3}$ ). These two pieces of evidence strongly suggest that the local variability in $\mathrm{XCH}_{4}$ has a much larger footprint than the underlying local region. Therefore, any causal argument for a correlation between $\mathrm{XCH}_{4}$ observations from space and local surface emissions needs to account the effect of long-range atmospheric transport.

\footnotetext{
${ }^{1}$ Joint Institute for Regional Earth System Science \& Engineering, University of California, Los Angeles, Los Angeles, CA, USA. ${ }^{2}$ Division of Geological and Planetary Sciences, California Institute of Technology, Pasadena, CA, USA. ${ }^{3}$ Jet Propulsion Laboratory, California Institute of Technology, Pasadena, CA, USA. ${ }^{4}$ Zhejiang Climate Center, Hanzhou, China. ${ }^{5}$ Key Laboratory of Digital Earth Science, Aerospace Information Research Institute, Chinese Academy of Sciences, Beijing, China. ${ }^{凶}$ email: zcz@gps.caltech.edu; brendan.k.byrne@jpl.nasa.gov
} 
(a)
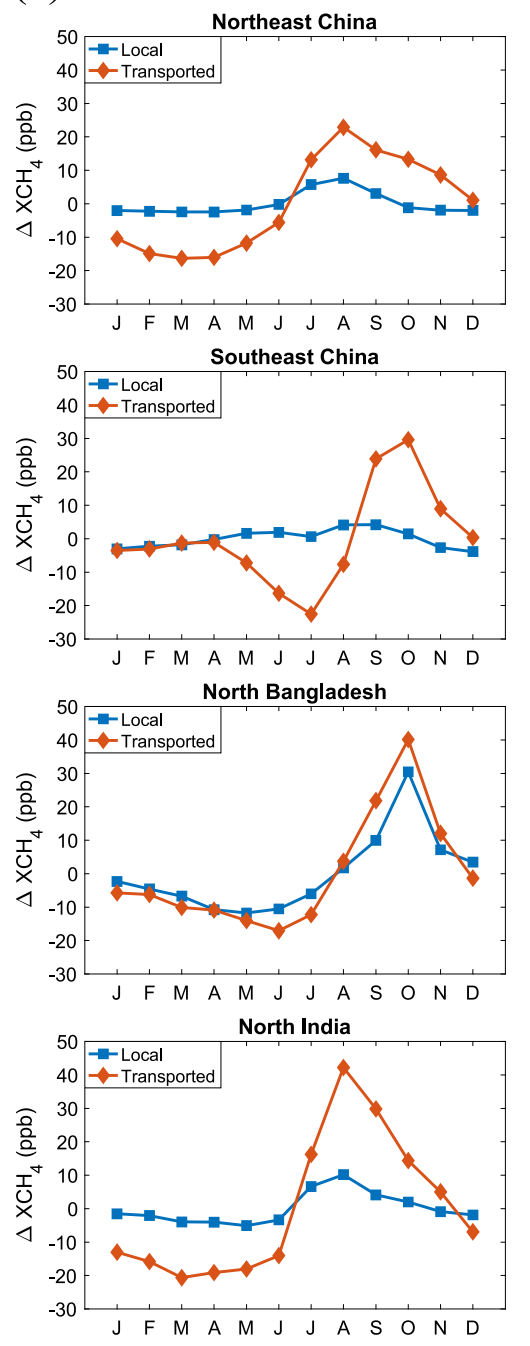

(b)
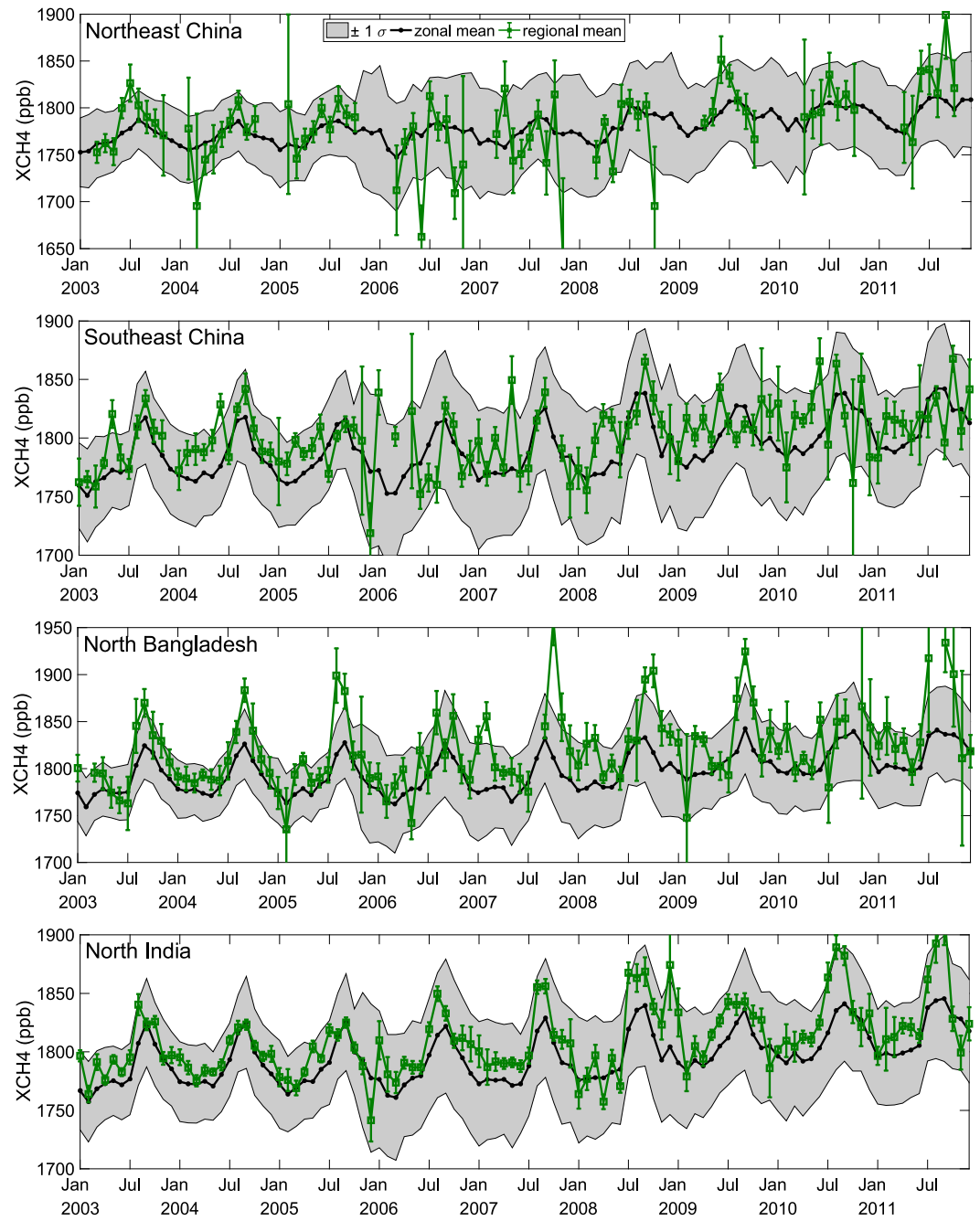

Fig. 1 Measured and modeled monthly $\mathbf{X C H}_{\mathbf{4}}$ for four regions. a The relative contributions of local $\mathrm{CH}_{4}$ emissions (local) and external $\mathrm{CH}_{4}$ emissions (transported) to the seasonal cycle of $\mathrm{XCH}_{4}$ in the four regions of interest (ROIs). These contributions are estimated using the Greenhouse Gas Framework-Flux (GHGF-Flux; see "Methods") $\mathrm{CH}_{4}$ model. The description of the model and related analysis is presented in "Methods". b The monthly averaged $\mathrm{XCH}_{4}$ in four ROls: Northeast China, Southeast China, North Bangladesh, and North India, the same with the ROls in Fig. 3a-d of Zhang et al. 1 . The error bars are the monthly uncertainties calculated by error propagation from the uncertainties in $\mathrm{XCH}_{4}$ retrievals in a certain month; zonal means which are the averaged $\mathrm{XCH}_{4}$ over the latitudinal band centered in the ROIs and the uncertainty estimate by one standard deviation in the shaded background are overlaid. The zonal latitudinal bands are $40^{\circ}-50^{\circ} \mathrm{N}, 23^{\circ}-33^{\circ} \mathrm{N}, 20^{\circ}-30^{\circ} \mathrm{N}$, and $20^{\circ}-30^{\circ} \mathrm{N}$, respectively, for the four ROls. The correlation coefficients between the zonal means and regional means are $0.53,0.50,0.73$, and 0.83 , respectively, with all $p$ values less than 0.01 from the significance tests of the linear regression relationship.

Zhang et al. ${ }^{1}$ also claimed that the spatial distribution of rice paddies was a major factor in determining the spatial $\mathrm{XCH}_{4}$ distributions in monsoon Asia based on their spatial consistencies. However, there is also spatial consistency between $\mathrm{XCH}_{4}$ and the non-agriculture fluxes, and cross-correlation between agriculture and non-agriculture $\mathrm{CH}_{4}$ fluxes. From our analysis based on the emission database for global atmospheric research (EDGAR) reanalysis data as shown in Fig. 2a, the spatial correlation between non-agriculture $\mathrm{CH}_{4}$ emissions and $\mathrm{XCH}_{4}$ in Monsoon Asia is higher than that between agriculture and $\mathrm{XCH}_{4}$. It indicates the rice paddy emission may not be the most important factor regulating the spatial distribution of $\mathrm{XCH}_{4}$ in Monsoon Asia. Moreover, the non-agriculture and agriculture $\mathrm{CH}_{4}$ emissions are strongly cross-correlated in space (Fig. $2 \mathrm{~b}$ ) since agricultural lands in Monsoon Asia are usually close to the non-agriculture sources, which mainly include anthropogenic sources (energy and fossil fuel production) and waste and wastewater sources $^{8}$. Such a strong cross-correlation should be accounted for when inferring a relationship between the spatial structure of $\mathrm{XCH}_{4}$ and agricultural flux, given that the nonagriculture sources in Asia are also highly variable in both space and time 9 .

Altogether, our re-analysis of the $\mathrm{XCH}_{4}$ observations combined with atmospheric transport model simulations suggests the need for caution in using correlation-based inference to quantify the change of paddy rice $\mathrm{CH}_{4}$ emissions from the simple relationship between the area and growth of paddy rice and satellite-observed $\mathrm{XCH}_{4}$. We suggest that combining satellite observations and model simulations in a data assimilation system (e.g., ref. ${ }^{10}$ ) is needed to disentangle the influence of local rice paddy emissions from other sources within the region and large scale advected signals. 
(a)

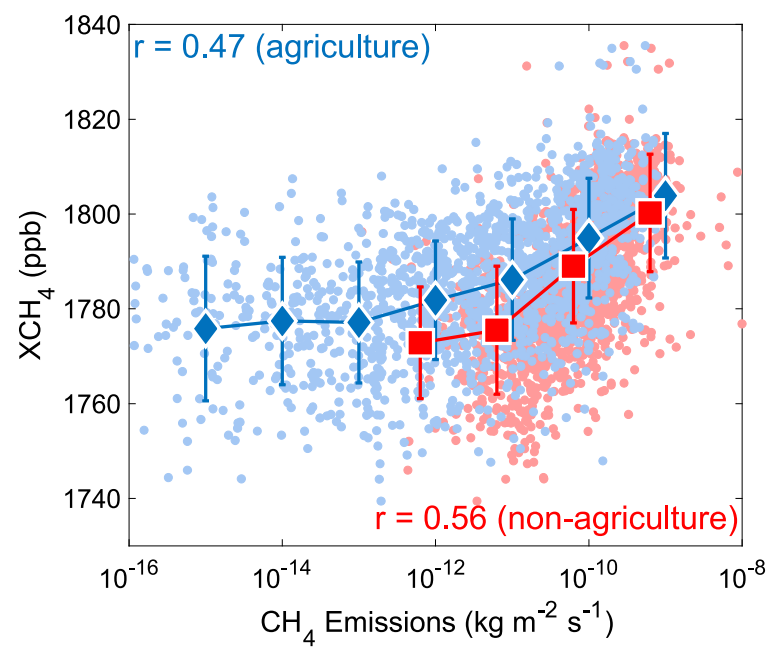

(b)

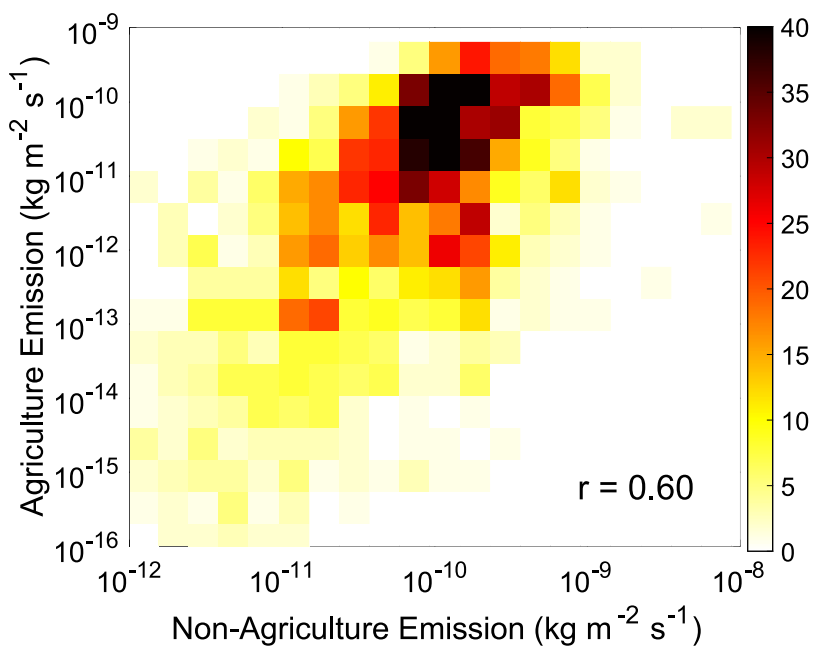

Fig. 2 Correlations between emissions and column abundances. a The correlation between $\mathrm{XCH}_{4}$ observed by the space-based instrument $\mathrm{SCanning}$

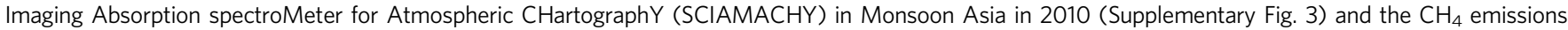
from all sectors (Supplementary Fig. 4a) except agriculture (non-agriculture) and agriculture soil (agriculture; Supplementary Fig. 4b), respectively. The correlation coefficients $(r)$ are also indicated. The error bar is defined as the standard deviation for each group of observations divided by the $\mathrm{CH}_{4}$ emissions. b The bivariable histogram between agriculture and non-agriculture $\mathrm{CH}_{4}$ emissions in Monsoon Asia in 2010 . The correlation coefficient (0.60) is also indicated. The $\mathrm{CH}_{4}$ emission data are obtained from the Emission Database for Global Atmospheric Research (EDGAR) bottom-up inventory in 2010.

\section{Methods}

Datasets. The IMAP v7.2 $\mathrm{XCH}_{4}$ data product from SCIAMACHY retrievals, which were downloaded from the ESA GHG-CCI data portal (http://www.esa-ghgcci.org/). The $\mathrm{XCH}_{4}$ data from 2003 to 2011 are used for analysis in this study. The EDGAR methane emission bottom-up inventory data are obtained from The Emissions Database for Global Atmospheric Research (EDGAR) (https://edgar.jrc. ec.europa.eu/overview.php? $\left.\mathrm{v}=432 \_\mathrm{GHG}\right)$. The annual sector-specific grid map in 2010 for total $\mathrm{CH} 4$ flux and for agriculture soil is used in this study.

Tagged Tracer simulations using GHGF-Flux simulation of CH4. Tagged tracer simulations were performed with the GHGF-Flux forward model. GHGF-Flux is a flux inversion system developed under NASA's Carbon Monitoring System project. The GHGF is capable of simulating $\mathrm{CH}_{4}, \mathrm{CO}, \mathrm{CO}_{2}$, and OCS and inherits the chemistry transport model from the GEOS-Chem. Chemical transport is driven by the Modern-Era Retrospective Analysis for Research and Applications, Version 2 (MERRA-2) meteorology produced with version 5.12.4 of the GEOS atmospheric data assimilation system ${ }^{11}$. To perform tracer transport, these fields are regridded to $2^{\circ} \times 2.5^{\circ}$ horizontal resolution and archived with a temporal resolution of $3 \mathrm{~h}$ except for surface quantities and mixing depths, which have a temporal resolution of $1 \mathrm{~h}$. Tracer transport is performed at 15 min time steps. Surface $\mathrm{CH}_{4}$ emissions were taken to be the total posterior $\mathrm{CH}_{4}$ flux from CarbonTracker- $\mathrm{CH}_{4}$ for $2010^{10,12}$, regridded to the $2^{\circ} \times 2.5^{\circ}$ model resolution. Global $\mathrm{OH}$ fields were obtained from the Global Modeling Initiative model simulation run with MERRA reanalysis. With these sources and sinks $\mathrm{XCH}_{4}$ is simulated over 2010-2015 (using repeated 2010 surface fluxes). Simulations are performed with surface fluxes at every model grid cell and local fluxes only for the four ROIs, from which the local and transported $\mathrm{XCH}_{4}$ signals are isolated. For the $\mathrm{XCH}_{4}$ simulation the ROIs are approximated as latitude-longitude boxes (see Supplementary Fig. 1). The North China box is bounded by $45^{\circ}-59^{\circ} \mathrm{N}$ and $128.75^{\circ}-136.25^{\circ} \mathrm{E}$; North India is bounded by $25^{\circ}-35^{\circ} \mathrm{N}, 68.75^{\circ}-81.25^{\circ} \mathrm{E}$; the North Bangledesh is bounded by $19^{\circ}-25^{\circ} \mathrm{N}$ and $86.25^{\circ}-93.75^{\circ} \mathrm{E}$; and Southeast China is bounded by $25^{\circ}-29^{\circ} \mathrm{N}$ and $113.75^{\circ}-121.75^{\circ}$ E. The 6 -year $\mathrm{XCH}_{4}$ time series are then detrended and averaged across the 6 years to obtain a mean seasonal cycle (see Supplementary Fig. 5). Note that simulated $\mathrm{XCH}_{4}$ is calculated using a column averaging kernel with a value of 1 for every level.

\section{Data availability}

CarbonTracker- $\mathrm{CH}_{4}$ results are provided by NOAA ESRL, Boulder, Colorado, USA (http://www.esrl.noaa.gov/gmd/ccgg/carbontracker-ch4/); The IMAP v7.2 data product from SCIAMACHY from the ESA-CCI data portal (http://www.esa-ghg-cci.org/); the EDGAR methane emission bottom-up inventory data are provided by the European Commission (https://edgar.jrc.ec.europa.eu/overview.php?v=432_GHG). Results from model simulations are available via an open-access link at https://doi.org/10.5281/ zenodo.4291324.
Received: 28 May 2020; Accepted: 19 January 2021; Published online: 19 February 2021

\section{References}

1. Zhang, G. et al. Fingerprint of rice paddies in spatial-temporal dynamics of atmospheric methane concentration in monsoon Asia. Nat. Commun. 11, 1-11 (2020).

2. O'Dell, C. W. et al. The ACOS CO2 retrieval algorithm-part 1: description and validation against synthetic observations. Atmos. Meas. Tech. 5, 99-121 (2012).

3. Frankenberg, C. et al. Global column-averaged methane mixing ratios from 2003 to 2009 as derived from SCIAMACHY: trends and variability. J. Geophys. Res. 116, D04302 (2011).

4. Byrne, B. et al. Sensitivity of $\mathrm{CO}_{2}$ surface flux constraints to observational coverage. J. Geophys. Res. Atmos. 122, 6672-6694 (2017).

5. Keppel-Aleks, G., Wennberg, P. O. \& Schneider, T. Sources of variations in total column carbon dioxide. Atmos. Chem. Phys. 11, 3581-3593 (2011).

6. Liu, J., Bowman, K. W. \& Henze, D. K. Source-receptor relationships of column-average $\mathrm{CO} 2$ and implications for the impact of observations on flux inversions. J. Geophys. Res. Atmos. 120, 5214-5236 (2015).

7. Jacob, D. J. Introduction to Atmospheric Chemistry. (Princeton University Press, 1999).

8. Janssens-Maenhout, G. et al. EDGAR v4.3.2 Global Atlas of the three major greenhouse gas emissions for the period 1970-2012. Earth Syst. Sci. Data 11, 959-1002 (2019).

9. Peng, S. et al. Inventory of anthropogenic methane emissions in mainland China from 1980 to 2010. Atmos. Chem. Phys. 16, 14545-14562 (2016).

10. Bruhwiler, L. et al. CarbonTracker- $\mathrm{CH}_{4}$ : an assimilation system for estimating emissions of atmospheric methane. Atmos. Chem. Phys. 14, 8269 (2014).

11. Gelaro, R. et al. The modern-era retrospective analysis for research and applications, version 2 (MERRA-2). J. Clim. 30, 5419-5454 (2017).

12. Peters, W. et al. An atmospheric perspective on North American carbon dioxide exchange: CarbonTracker. Proc. Natl Acad. Sci. USA 104, 18925-18930 (2007).

\section{Acknowledgements}

Z.Z. would like to thank Yuk Yung at Caltech and Stan Sander at JPL for their strong supports and stimulating discussions on greenhouse gas remote sensing. BB's research 
was supported by an appointment to the NASA Postdoctoral Program at the Jet Propulsion Laboratory, administered by Universities Space Research Association under contract with NASA. BB's research was carried out at the Jet Propulsion Laboratory, California Institute of Technology, under a contract with the National Aeronautics and Space Administration (80NM0018D0004).

\section{Author contributions}

Z.Z. designed the study, conducted the analysis of satellite observations, and wrote the first draft. B.B. performed the model simulation and data analysis and wrote the draft. F.G. and Z.H. conducted the initial analysis of the original study by Zhang et al. L.L. interpreted the analysis of satellite observations. All co-authors collaborated in the interpretation of the results and editing of the paper.

\section{Competing interests}

The authors declare no competing interests.

\section{Additional information}

Supplementary information The online version contains supplementary material available at https://doi.org/10.1038/s41467-021-21434-7.

Correspondence and requests for materials should be addressed to Z.-C.Z. or B.B.
Peer review information Nature Communications thanks Tor Grande, Wook Jo and Sunil Kumar for their contribution to the peer review of this work. Peer reviewer reports are available.

Reprints and permission information is available at http://www.nature.com/reprints

Publisher's note Springer Nature remains neutral with regard to jurisdictional claims in published maps and institutional affiliations.

(c) (i) Open Access This article is licensed under a Creative Commons Attribution 4.0 International License, which permits use, sharing, adaptation, distribution and reproduction in any medium or format, as long as you give appropriate credit to the original author(s) and the source, provide a link to the Creative Commons license, and indicate if changes were made. The images or other third party material in this article are included in the article's Creative Commons license, unless indicated otherwise in a credit line to the material. If material is not included in the article's Creative Commons license and your intended use is not permitted by statutory regulation or exceeds the permitted use, you will need to obtain permission directly from the copyright holder. To view a copy of this license, visit http://creativecommons.org/licenses/by/4.0/.

(c) The Author(s) 2021 